\title{
Reflections on autonomy in travel for cross border reproductive care
}

\section{Anita Stuhmcke ${ }^{1}$}

Abstract Travel for reproductive health care has become a widespread global phenomenon. Within the field, the decision to travel to seek third parties to assist with reproduction is widely assumed to be autonomous. However there has been scant research exploring the application of the principle of autonomy to the experience of the cross-border traveller. Seeking to contribute to the growing, but still small, body of sociological bioethics research, this paper maps the application of the ethical principle of autonomy to the lived experience of infertile individuals who cross borders for reproductive care. It examines their choices as patient, consumer and traveller. It suggests that their experience evidences a contradictory autonomy, which offers them both choice and no choice in their final decision to travel. The paper argues that this lack of meaningful autonomy is enabled by a medicalised framework of infertility which prioritises technology as the cure to infertility. This both shapes expectations of infertile individuals and limits their options of family creation. Ultimately, the paper suggests that sociology bioethics research shows that the liberatory credentials of technology should be questioned, and identifies that this field demands greater scholarly attention.

Keywords Autonomy, Cross border reproductive care, Bioethics, Infertility, Reproduction

Email: Anita.Stuhmcke@uts.edu.au

Phone: +61 295149658

\footnotetext{
${ }^{1}$ Faculty of Law, University of Technology, Sydney, Australia
} 


\section{Introduction}

Cheryl (\#21) was married in 2010. Over the next four years she underwent 13 rounds of In Vitro Fertilisation (IVF). Her doctor(s) advised her to 'just keep going, there's nothing wrong with you, just keep going it will work'. Cheryl underwent 'multitudes of tests'. Her IVF treatments occurred over multiple locations and doctors, and involved moving between Australian states to undergo treatments until 'we got to a point we thought we just can't. You've got to be an idiot to keep doing this over and over and over again with the same result.' Through Internet research, reading a textbook by an immunologist, and attending one surrogacy conference, Cheryl self-diagnosed that her immune system was 'killing' her embryo. Cheryl told researchers that 'in terms of support for surrogacy...I'd said to my doctors, "I don't feel like it's the embryos"; I feel like it's the implantations just not working.' Nevertheless, '[n]o one ever suggested surrogacy. No one ever said: 'have you got a sister or a friend or' - no one ever asked that.' Cheryl travelled to India, which was at that time a legal destination for international travellers seeking cross border reproductive care (CBRC), and was successful in having a baby by an Indian surrogate using her and her husbands' gametes, at a cost of AU $\$ 34,000$.

Cheryl is a traveller who engaged in CBRC to access reproductive technologies (ARTs), surrogacy and related treatments. Cheryl's narrative reveals three roles or identities of the CBRC traveller: (1) a patient consenting to the medical provision of IVF to cure infertility; (2) a consumer choosing to locate the best doctor and the right clinic; and (3) a traveller accessing the global ART industry. As will be explained, Cheryl's story is not unique amongst travellers seeking CBRC, but neither is it typical. Her story is not unique as, for many patients, treatment options are often both physically and mentally arduous, as well as expensive and time consuming. Her story is only typical in so far as fertility journeys vary 
widely in time taken, physical and emotional harm, and money spent. While Cheryl's story is hers alone, her experiences as a patient, consumer and traveller raise the issue of the extent and limits of autonomy shared by all individuals who travel across borders seeking ART.

This paper probes the application of the ethical principle of autonomy to the experience of infertile individuals seeking CBRC. Autonomy is an important value in reproductive decision making because it ensures that individuals make complex decisions which are of their own choice, and allows individuals to direct the course of their own life (Farrell et al. 2017; Morgan 1998; Nedelsky 1989). Health law prioritises patient autonomy, yet in bioethics little attention has been paid to individuals crossing borders to use reproductive health services, with even less consideration of their autonomy. The focus of research on health and travel for CBRC is generally upon health issues which arise once travel has taken place, such as the impact upon donors' health (Jordan et al. 2004), or the involvement of the local domestic professional (Snyder et al. 2013; Millbank 2019). This paper extends this scholarship by examining autonomy in the decision making process prior to travel.

Through an interview-based qualitative study with individuals who travel, often illegally, for $\mathrm{CBRC}$, this paper offers insight into the practical application of the ethical principle of autonomy. The study confirms that infertile individuals make choices within a medicalised framework which shapes expectations and drives choice in family creation. Our findings support assertions made by medical sociologists that medicalisation may lead to a harmful loss of control (Morgan 1998: 83-121). This is exemplified in Cheryl's narrative. Each of her experiences across the three sites of patient, consumer and traveller contains an inherent contradiction. Firstly, Cheryl's consent to infertility treatment as an IVF patient belies the reality of the financial, physical and mental harm inflicted upon her by repeated and failed medical treatments; secondly, her choice of treatment and clinical practitioner is made complex due to territorial and treatment limitations under Australian law, and how such 
treatment is limited by the business model of fertility clinics; and finally, her 'independent' decision to travel is made against a backdrop of risk and fear.

Discussion of autonomy in ART is increasingly important. Infertility rates are rising (FertilitySA 2018), global travel is proliferating (Culley et al. 2011), and ART is normalized to such a degree that processes such as oocyte freezing are offered as an 'insurance' against future infertility. Autonomy also needs to be considered in the context of the harm that occurs to both the traveller and to third parties, as well as the financial, physical and mental costs to donors and surrogates. A recent study of international literature conducted by Hodson and Bewley found a range of incidents of health abuse in ART, including unnecessary medical procedures, the absence of a concerted public health campaign regarding infertility, and a lack of promotion of alternative ways to start a family, such as intrauterine insemination or adoption, leading to couples using ART without first trying conservative measures (Hodsona and Bewley 2019). Abuse is also apparent in the Australian ART industry. In March 2019, the Minister for Health in the state of Victoria referred an inquiry under section 103 of the Health Complaints Act 2016 (Vic) into the provision of ART services. The Terms of Reference of the inquiry covers potentially dangerous and unethical practices of ART providers, the use of "add-ons" or "adjuvant therapies" not medically proven to be effective, and potential misleading and deceptive conduct in relation to advertisement of costs and success rates.

This paper is part of a growing body of empirical work contributing to bioethical inquiry. This paper is not a rights-based argument for reproduction or to travel for CBRC. Instead, it uses the actual experience of infertile individuals who have travelled for CBRC to determine whether and how external constructs influence the travellers' autonomous decision-making. To begin, I outline the background of ART and CBRC, explain the research study, and note its usefulness in the context of sociological bioethics. I then briefly explain the ethical 
principle of autonomy and flag its known limits in existing bioethical and feminist scholarship in relation to reproductive autonomy. The findings of the research are then provided, supporting the view that autonomy in this area is contradictory, as individuals who travel for CBRC clearly exercise choice, but are also influenced by external factors which may reduce and limit autonomy and 'push' Australians overseas for CBRC. In conclusion, I urge the reframing of regulation to assist infertile individuals create families within Australia (Pennings et al. 2008).

\subsection{Cross Border Reproductive Care (CBRC) and Australians travelling for ART}

Reproductive travel typically refers to services involving medically assisted conception, and is often framed as a subset of medical tourism or travel to obtain health care. It is a fastgrowing industry, worth more than US\$22.3 billion globally (Global Market Insights 2016: 2016-2023), with dozens of countries emerging as destinations.

Terms such as 'reproductive travel', 'fertility tourism' and 'holiday' are used in existing literature to reflect an element of choice, depict the travel as a leisurely activity (Speier 2016), and imply free and easy travel, and individual choice-as-pleasure (Franklin 1997). However, these terms are contentious. Some scholars argue that the terms misrepresent the risks of cross-border travel, as well as obscure the desperation that informs the choice to cross borders for assisted fertility services. Instead, they suggest the use of terms such as 'reproductive exile' (Inhorn and Patrizio 2009), or 'repro-migration' (Nahman 2011). In recognition of this debate, this paper avoids the use of the term 'tourism' and instead uses 'cross border reproductive care', adopting the terminology used by Royal Australian and New Zealand College of Obstetricians and Gynaecologists (RANZCOG) (2016). CBRC has 
been an influential concept and the accepted term within the clinical literature, although care may be lacking in instances of transnational reproduction.

The numbers of Australians travelling for CBRC is unknown. The most recent inquiry into ART in the Australian state of Victoria stated that '.... a large, but unquantified, number travel overseas for ART' (Gorton 2019). The existing policy framework in Australia therefore fails to prevent and reduce reproductive travel. Theoretically, a strong regulatory approach has a general deterrent effect on the behaviour of would-be violators (Ross 1982; 1992). The prevalence of travel for CBRC suggests that dilemmas and risks associated with travel are not removed by strict legislation but are instead relocated. In Australia, three jurisdictions (New South Wales, Queensland and the Australian Capital Territory) have criminal penalties attached to cross border travel, while most jurisdictions prohibit commercial surrogacy. However, the existence of these penalties did not prevent our interviewees from illegally crossing borders. Travel for CBRC is likely to continue, as when patients know they can go elsewhere, they are less likely to protest against overly strict legislation, and legislators who find certain procedures objectionable may be more likely to enact or maintain overly restrictive regulations (Storrow 2010). Thus, when theorizing the ethics of reproductive technologies and the contradictions between state policies and individual desires, one must take care not to equate lack of regulation with more freedom and choice, and regulation with constraint.

\subsection{The Medicalisation of Infertility}

The global industry of assisted reproduction is predicated upon the classification of infertility as a disease of the reproductive system and its treatment through in vitro fertilisation (IVF). However, infertility was not always a disease; prior to the late 1970 s, it was generally seen as 
a social condition (Conrad et al. 2010), and society generally accepted it as natural but disappointing to be childless. Following the birth of Louise Brown, the first child born through IVF, in 1978, the medical fraternity began to identify infertility as a medical condition. The Australian state of Victoria became the first jurisdiction in the world to enact legislation regulating ART, with the Infertility (Medical Procedures) Act 1984 coming into effect in 1988 (Law Reform Committee 2012: xix). This legislation marked the beginning in Australia of legal protection of the infertile as a category of patient, and regulation of fertility clinicians.

This process, whereby a social issue becomes a medical condition, is described by medical sociologists as medicalisation. Conrad defines this as where 'nonmedical problems become defined and treated as medical problems, usually in terms of illness or disorders' (Conrad 1992). Infertility is now defined by the World Health Organisation as 'the failure to achieve a clinical pregnancy after 12 months or more of regular unprotected sexual intercourse' (World Health Organization n.d.; see also Montgomery 2016), and is common issue, with a global prevalence of approximately 9 per cent (Leyser-Whalen et al. 2018: 446). ${ }^{2}$ For these infertile individuals, it is 'now expected that infertility is something to be overcome' (Bell 2010: 634), with technology offered as a solution (Sandelowski 1991). As Franklin observes, technology '... is positioned as a helpmate to nature: it allow[s] fertilisation to occur' (Franklin 1975: 175), such that other options for family creation - adoption, fostering and childlessness - are seen as second best and even characterised as an admission of failure (Donhcin 2011).

The reasons as to why individual patients cross borders, often illegally, for reproductive care are described as 'push pull' factors (Jackson et al. 2017). For example, in Cheryl's case there is the 'push' factor of the absence of care in Australia, and the 'pull' factor of

\footnotetext{
${ }^{2} 51.8$ per cent of women aged 25-45 report infertility at some point in their lives and fewer than 50 percent of infertile women receive medical treatment (Greil et al. 2011).
} 
commercial surrogacy being available in India. Cheryl was able to circumvent the conditions of Australia by choosing a surrogate mother in India, where her and her husband had cheaper services and sole parental rights. However, as standards of labour are higher in Australia, the Indian surrogate is subject to practices that would not have been tolerated had she been an Australian citizen.

The economic power imbalance between the traveller and the third parties who assist them to create a family, such as a surrogate or a gamete donor, creates an assumption that reproductive travellers act from a position of power. Citizens of a nation state are thus transformed into stateless global consumers, able to buy their way out of inconvenient or onerous domestic policies including restrictive regulations, expensive treatment and long waiting lists. Reproductive travel is emphasised as a personal choice, made because of opportunities offered in destination countries such as donor anonymity, level of service, or access to services not available in the home jurisdiction like commercial surrogacy or sex selection.

\subsection{The Study: sociological bioethics}

This paper draws upon a larger empirical study of the lived experiences of Australians who travel to undertake CBRC. The study has a patient centred approach which is informed by social scientific studies rather than being clinically oriented (Greil et al. 2010). The focus was Australians who cross borders, nationally or internationally, and legally or illegally. A total of 93 interviews were conducted. Of these, 37 interviews were with people who had travelled overseas, to countries including India, Thailand, Nepal, Mexico, Spain, South Africa, Greece, Canada and the USA; ten interviewees travelled to more than one country. A further 19 had 
crossed borders within Australia to access services. This paper focuses upon these 56 interviewees.

A conventional content analysis was used to analyse the collected data. All interviews were tape-recorded and transcribed verbatim. Interviews were entered, without identification, into NVIVO software to enable thematic coding and analysis. Pseudonyms are used in this paper. All three investigators contributed to coding themes and held multiple meetings to discuss and cross-check coding to ensure consistency of approach.

This paper uses a deductive thematic analysis (Bartholomaeus and Riggs 2018) to focus upon the issue of autonomy with respect to those 56 interviewees who engaged in crossborder travel. The analysis is based upon the shared identities of the traveller as patient, consumer and traveller. Only a small number of interviewees - around 10 - knew they were medically unable to have children before embarking on treatment. These 10 individuals are a combination of socially infertile, for example being gay, or medically infertile, for example not having a uterus. As socially infertile individuals across most Australian jurisdictions are able to access ARTs (Bell 2010), all interviewees share the attributes of patient (even if they themselves are not treated), consumer and traveller.

Like Paton (2018), I believe that bioethical inquiry can be 'done' under the auspices of sociology. As such, this paper uses the in-depth interviews with both men and women from this cohort to explore autonomy, and takes a socio-legal approach to advance empirical bioethics. It is also part of a growing body of empirical work contributing to bioethical inquiry (Wangmo and Provoost 2017). In facilitating the production of personal knowledge and applying it to the structures within which the choice to travel for CBRC is made, I explore the limits and the operation of autonomous choice making in cross-border reproductive care. This is a bottom-up approach, as arguably an understanding of the 
application of the ethical principle of autonomy emerges only from the lived experience of individuals.

\subsection{Autonomy and reproductive autonomy: a brief overview}

The preservation and promotion of autonomy, which in general terms allows individuals to direct the course of their own life, is a key concern in the provision of individualized, patientcentered, ethical health care. In the language of Milligan and Jones, in health care autonomy is the 'principal principle' (Milligan and Jones 2017). In Australia, respect for autonomy by health professionals is a key principle of the common law where courts have had to consider the implications of reproductive autonomy in cases concerning surrogacy agreements $(R e$ Evelyn 1998), and the use of a male partner's stored semen after his death (Creswell v Attorney-General for the State of Queensland 2018). It is also a key concept in biomedical ethics, and underpins the National Health and Medical Research Council's 'Ethical guidelines on the use of assisted reproductive technology in clinical practice and research (ART guidelines)' governing the delivery of fertility services. ${ }^{3}$

However, while the term autonomy is the principle principal in health care. it is not easy to define (see e.g. Sandel 1982; Sherwin 1998: 19; Schneider 1998). In bioethics literature there is 'no theory of autonomy that spells out its nature, its moral implications, its limits...' (Beauchamp 2004: 214). As Dworkin explains, we have 'one concept and many conceptions of autonomy...' (Dworkin 1988: 9), with the term being used in:

... an exceedingly broad fashion. It is sometimes used as an equivalent of

liberty (positive or negative in Berlin's terminology), sometimes as

\footnotetext{
${ }^{3}$ While less relevant for Australia's domestic legal system support for reproductive autonomy is found in international instruments (such as the International Convention on Civil and Political Rights, the Convention on the Elimination of Discrimination Against Women, the International Conference on Population and Development, and the European Convention on Human Rights).
} 
equivalent to self-rule or sovereignty, sometimes as identical with freedom of the will. It is equated with dignity, integrity, individuality, independence, responsibility and self-knowledge. It is identified with qualities of self assertion, with critical reflection, with freedom from obligation, with absence of external causation, with knowledge of one's own interests.... It is related to actions, to beliefs, to reasons for acting, to rules, to the will of other persons, to thoughts and to principles. About the only features held constant from one author to another are that autonomy is a characteristic of persons and that it is a desirable quality to have. (Dworkin 1988: 9)

Dworkin's framing of autonomy as a desirable quality originates in the work of Immanuel Kant, who argued that respect for autonomy flows from 'the recognition that all persons have unconditional worth and the capacity to determine their own moral destiny' (Beauchamp and Childress 2001). Kant's framework is one where autonomy is focused upon individual choice, allowing the individual to navigate their lives with the freedom to do what they wish. This traditional understanding of autonomy is applied in bioethics. Beauchamp and Childress (2009), who developed the principles of justice, non-maleficence and beneficence in bioethics, define personal autonomy in a Kantian way: 'self rule that is free from both controlling influence by others and from limitations, such as inadequate understanding, that is present in meaningful choice' (Beauchamp and Childress 2001: 57-112). However, Beauchamp and Childress also recognise that internal and external forces impact autonomy. In recognising limitations on autonomy, Beauchamp and Childress depart from Kantian constructions of autonomy and adopt the John Mills' understanding of state limitations on personal liberty (Mill 1909). These limits restrict the two essential conditions for autonomy, liberty and agency (Beauchamp and Childress 2001: 57-112). 
This paper begins from Beauchamp and Childress' acceptance of limits upon autonomy. It uses this concept to explore the forces which curtail reproductive autonomy. Reproductive autonomy is simultaneously a 'negative' freedom, such as with legal abortion where third parties are stopped from restricting individual reproductive choices, as well as a 'positive' freedom that requires facilitation of reproductive liberty (Robertson 1994). Yet neither form fully explains the application of autonomy to CBRC. For example, in the case of Cheryl, who decided to use a surrogate in India, a choice was made to pursue surrogacy. However, this decision also involved a choice to use another person's body. This raises complex questions such as: is it ever an exercise of autonomy to use another's body for a medical procedure for reproduction? How is it a personal right to procreate when someone else must be employed to do so? Is that autonomous? On the other hand, CBRC for both Cheryl and the third parties who assist her in reproduction may equally create opportunity for genuine autonomy.

This contradiction in reproductive autonomy has long been flagged by feminist scholars, who are unable to agree on which scenario is correct. Access to reproductive technology is not characterised as a feminist issue of reproductive freedom, nor is there a unified feminist response. This is despite that fact that while reproductive autonomy is important to both men and women, it is particularly significant for women, with respect to intrusiveness of treatment, because childbearing takes place in women's bodies, and reproduction has many consequences for women's lives (Purdy 2006). The absence of a unified feminist response arises in part due to an inability to agree as to how autonomous women's choice making really is. Firestone, for example, envisioned that reproductive technologies could be used as a tool to liberate women from the birth process and the corollary responsibility of childrearing (Firestone 1970), whereas at the other end of the spectrum, Corea (1985) equated reproductive technology with high-tech prostitution and the degradation of women. Additionally, aspects of reproductive travel have been decried for their ethical implications 
which brush against autonomy. For example, travel by the wealthy exploits the poor, with such exploitation undermining the laws and policies (and thus sovereignty) of nation-states, and reinforcing existing global inequalities (Waldby and Cooper 2008).

\subsection{Brief review of literature}

The ethics of CBRC is well traversed (Pennings et al. 2008). According to Couture et al., CBRC has generated an important ethical literature mostly addressing four families of issues: (1) ethico-legal, (2) medical ethics, (3) feminist ethics, and (4) cellular ethics. Despite this, they note that in 2019 'the conclusions are still based on scarce evidence even considering the global scale of CBRC. Empirical ethics appears as a way to foster this ethical reflection on CBRC while attuning it with the experiences of its main actors' (Couture et al. 2019: 41). This echoes the call made by Inhorn and Patrizio (2012) for what they said is a 'most urgent need...for more empirical research, both quantitative and qualitative in nature' (Inhorn and Patrizio 2012). There is also a scarcity of evidence in Australia. The empirical research that has been undertaken as to travel for $\mathrm{CBRC}$ is focused upon the third party who assists in reproduction, such as the egg donor or surrogate (Whittaker and Speier 2010: 364; Waldby 2019), or on issues such as donor choice. The autonomy of the traveller is generally assumed rather than explored.

Importantly, this paper is a bioethical inquiry which engages with scholarship on the ethics of ART more broadly. It suggests that the autonomy of travellers for CBRC is restricted and contradictory but does not advocate a 'right' to medical travel or a 'right' to procreate, nor is it an attack on autonomy (Foster 2009; Fox and Swazey 2008; McLean 2010). In keeping with the interdisciplinary nature of bioethical inquiry, it draws upon medical sociologists, anthropologists, and the relational understandings of feminist legal 
scholars (Farrell et al. 2017; Morgan 1998), to assess the adequacy of the liberal notion of autonomy. It argues that autonomy does not work where the medicalisation of infertility masks the role of technology and science, undermining understandings of the context within which choices are made. This argument builds upon Meyers' (1989) understanding that autonomy involves skills matched to the external environment within one must make choices. This restriction is apparent across all three categories of patient, consumer, and traveller for CBRC. Further, the interviews evidence marginalisation of infertile individuals, and show that the decisions they make are based upon a lack of self-worth and an over emphasis on belief in the miracle of the technologies provided by the medical profession. Reduced selftrust further impacts one's ability to act autonomously. In this way, the interviewees internalise society's attitudes and doubt their own ability to make good decisions (Mackenzie and Stoljar 2000: 263).

\section{The Patient, the Consumer and the Traveller: the limits of autonomy}

The bioethical principle of autonomy is consistently used to frame travel for CBRC. For example, the Australian medical profession supports the autonomy of individuals who travel for CBRC stating that '... all parties must be provided with appropriate information and counselling to make an informed decision whether to proceed to CBRC' (Royal Australian and New Zealand College of Obstetricians and Gynaecologists 2016). This section probes the application of autonomy to travellers for CBRC across their identities as patients, consumers and travellers. Using the interviews, it establishes that the treatment process, from the perspective of users, is confusing, complex, expensive and harmful. This compromises their ability to make autonomous decisions.

\subsection{The Patient and the Non-Patient}


In Australian health law, consent is the process through which autonomy is realised. The provision of consent is not just based upon a legal or moral right to make decisions for oneself, but is also an ethical obligation for doctors to treat patients with trust and dignity. Patients should trust that the health care professional will act honestly and for the well-being of the patient, and that the patient's wishes will be respected and supported. Patient faith in the medical profession is a pillar of the Australian medical system. As the Medical Board of Australia states, 'trust in the relationship between doctors and patients is a cornerstone of good medical practice' (Medical Board of Australia 2018). The Australian Code of Conduct for Doctors similarly observes that 'patients trust their doctors because they believe that, in addition to being competent, their doctor will not take advantage of them and will display qualities such as integrity, truthfulness, dependability and compassion' (Australian Medical Council 2009). Organisational factors have been recognised as important in maintaining patient faith: personnel styles, availability and respect afforded by both administrative and clinical staff, reasonable waiting times, and attention to personal comfort (Dorr Goold and Lipkin 1994).

\subsubsection{Loss of faith: organisational factors}

Women in our study who had undergone IVF treatment expressed a loss of faith in the medical profession across all organisational factors. Sometimes this loss was attributed to a difference of opinion between the patient and doctor, as Cybil explained: '[the doctor] just refused to entertain any difference. I had to leave him. I was like I can't have you as my ob/gyn if you can't even accept this, sorry, bye'. Other times it was the absence of a valued personal characteristic, as articulated by Maria: 'Australia, it wasn't what I expected. I expected people to be much more helpful. First of all, just the clinics to have more compassion and be more compassionate towards people in my situation.' Still, for others it 
was an absence of information, the essence of consent, as Olivia said: 'I was given very little information about whether my eggs would be viable and everyone was just encouraging me to do more cycles of IVF.'

For others it was frustration with the administration of the process. For example, in reference to a meeting of the Western Australian ethics committee to approve their application to undertake IVF, a husband and wife noted:

[I]t had actually got delayed a month because it was Christmas [they had decided not to meet]...it's awful feeling powerless in that position, where you really want something but when you're reliant on other people who, to me, just weren't professional, and weren't good at what they were doing. But then you had to put your trust in these people to have a child.

The above comments, ranging from the poor personal and professional care, to an absence of trust, typify the responses of interviewees. A relationship with doctors based upon trust and dignity was not evident amongst the interviewees, undermining the legal and medical framing of consent.

\subsubsection{Loss of faith: recurring harm and pain}

It just changes you and it changes you as a person. Like each cycle and each transfer you have, you lose a piece of yourself. Like it's like a little spark of you dies each time and you never get it back. Like it's just - you just wonder if you're ever going the happiness and your bubbliness and your outgoingness again, because it does - it just kills a piece of you every time you do it. (Rosalind)

Rosalind's observation, that IVF 'kills a piece of you', captures how infertility treatment exposes individuals to recurring harm and pain. Over the entire cohort of interviewees, every female interviewee who underwent IVF experienced a range of adverse events, such as 
multiple IVF attempts, recurrent miscarriages, financial costs of up to AU\$250,000, partner loss, and issues of self-esteem and worthlessness.

For all interviewees, fertility care was most often characterised as anything but care, and was instead experienced as a cascading ride of unsuccessful treatment. Once diagnosed as infertile, interviewees began with one treatment and ended up in a vastly different place. As May put it:

We've gone from hoping we could do it ourselves, to needing an egg donor, to needing a sperm donor, to using overseas eggs, to being fortunate enough to have access to some donor embryos, to possibly considering a surrogate, to considering a surrogate overseas.

May's statement traverses the entirety of ART treatments and surrogacy, revealing the extraordinary and unforeseen pathways that medicalised treatment can lead to. May's experience illustrates how her original consent to treatment set her down unexpected paths, with a consequent unwillingness or inability to stop treatment. Far from autonomy operating as a principle of protection in her treatment, the diagnosis of infertility led to an ongoing and uncertain treatment regime.

Ultimately, some interviewees ceased treatment due to receiving a diagnosis of 'unexplained fertility', or because they had become too old for treatment. As Rina, a heterosexual woman who was an intending parent through a surrogate, explains:

[T]he last three and a half years we've been going through IVF. So we had about 14 cycles with seven transfers... in August last year we were told we would need to look at a different pathway to try to have a baby. It took me probably six months to get my head around that and accept that was going to happen.

In reference to being told to look 'for a different pathway' by a doctor, Rina noted, 'that was probably the best thing that we've ever had happen in this journey is someone being 
really honest with us.' The inference here is that honesty from the medical profession, and a choice of alternate treatment options, had not been offered to Rina before that moment. Rina is dependent on doctors to tell her when to stop hoping. Yet health professionals may have little motivation to advise her to do so, especially for a private market-based ailment like infertility (Sandelowski 1991; Conrad and Leiter 2004). This will be discussed further in part 3.

The experience of not knowing when to stop treatment, and not being advised of alternative treatment pathways, was shared across interviewees. As Monique observes: [M]y husband, Alex, and I did 10 years of IVF - maybe nine years - with lots of transfers. So I think almost up to about 30 transfers. They weren't all stimulated cycles, and they said in the end, they said well you have lots of embryos, you're probably all right in that sense. Maybe you need to think about other options, so we decided we'll give surrogacy a go. So that worked first go.

Monique's experience typifies how the medical profession encouraged interviewees to keep using technology as a cure for their infertility. This is the case even following repeated failure. As Shirley explains:

The doctors couldn't identify any problem, couldn't work out why these 13 rounds of IVF that we did weren't working...We went to several different doctors in Sydney. We went to a doctor in Melbourne who has an interesting practice. I moved down to Melbourne for a month to do that. Nothing worked and the doctors kept saying, “just keep going, there is nothing wrong with you, just keep going it will work".

As a patient the doctors could find nothing wrong with Shirley. The treatment is not working yet she is encouraged to keep going. Technology is meant to help Shirley, yet it does the opposite. It does not help her through 13 rounds of IVF and yet her relationship to the 
treatment made it impossible to stop using it. As Franklin (2013) has observed, the existence of the technology makes it harder for individuals to reproduce without it. Shirley had to keep going until all avenues were exhausted. Ultimately Shirley went to India, used the couple's own embryos, and found success 'first time round'.

Shirley's experience highlights how the medicalisation of infertility acts to firstly, create the problem of infertility and secondly, hold out the promise for a medical cure for it. As Sandelowski (1991) argues, technology can be a boon and a burden for infertile couples as while the possibilities of a 'cure' have increased, so have the risks. One of those risks is that 'technology may reinforce suffering', as there is an increase in uncertainty because decisions around ending or changing the treatment cannot be made. The infertile individual is placed upon a trajectory of treatment through medical technology which begins with IVF and, as a successful live birth fails to materialise, will result in a plethora of tests and multiple treatments. These treatments can be difficult and painful. As Shirley, states she: went to a reproductive immunologist specialist here and took lots of drugs that were - you have to go into hospital overnight and have intravenous drips where they drip medicine into you which calms down your immune system. It's the same medicine they give transplant patients to help their body accept a new organ.

Shirley's inability to remove herself from medical treatment earlier than she did was due to a perceived absence of alternative options. Thus while technology seemingly created choices for her, it also reduced her ability to see alternative pathways.

\subsubsection{Experience of patients versus non-patients}

Inherent contradictions in the principle of autonomy as it applies to travellers for CBRC is clear when the experience of the 'patients' and 'non-patients' are juxtaposed. The non- 
patients are individuals excluded from medical treatment because they are socially infertile, for example gay men, or they are individuals who always knew they were medically infertile, for example women who have no uterus. These individuals are termed 'non-patients' as they are largely invisible to treatment providers given the irrelevancy of infertile medical services for them.

Our study shows that family creation was faster and easier for the cohort of non-patients than for patients undergoing IVF treatment. For example, for Tom, a gay man who undertook international surrogacy, the time between signing the contract to the birth of a child was ten and a half months. Similarly, for Harry and his partner, the process took 12 months, including the period prior to actually signing with agent and research time. Both partners engaged a surrogate using the same egg donor, and their twins were born on the same day. The process was also fast for Beth, a heterosexual woman who said: 'I knew that if I did want to have a child, surrogacy would be an option because I had eggs...so we were really lucky.'

The non-patient interviewees evidence less physical, emotional and financial harm as a result of total exclusion from medical treatment. This is not to infer that non-patients found the process to be simple, nor that they did not face difficulty in travel for CRBC. Rather a comparative approach reveals that on balance being marginalised from medical treatment results in less harm than those patients who were treated. Here the apparent contradiction arises that the principle of autonomy, designed to protect patients, results in increased harm for infertile individuals. This point is deserving of more research.

\subsubsection{The mismatch between medicine and the infertile individual}

While medicine constructs infertility as a medical condition, all of the interviewees framed their experiences as non-medical, with no interviewee referring to themselves as having a 
disease. Indeed, not one interviewee used the label of 'infertility' or 'infertile' to describe their experience. This finding - that infertile individuals reject the medical framing of their state as a disease - is in keeping with international research (see Leyser-Whalen et al. 2018).

Techniques used by interviewees to avoid references to infertility include factual references to an inability to have a child. For example, Penelope explained her miscarriages by saying: 'We've certainly never made it to the 12 -week mark. I think maybe once we made it to 10 weeks'. Penelope thus measures her pregnancies in weeks, rather than describing herself as infertile. Another interviewee, Beth, likened her ability to reproduce to a lawnmower. Beth is a heterosexual woman who had been diagnosed with cancer, but eventually became pregnant with twins. She observed that, '[d]ue to the cancer treatment, my ovaries weren't working very well, bit like a rusty old lawnmower that works sometimes and then wouldn't'. Beth's description reveals an important asymmetry between the medico-legal regulation framework and the application of it to the infertile individual. While the professions place importance on defining infertility, Beth rejects that and describes her ovaries as something that 'works sometimes'. In this way, Beth takes control of her identity as an exercise of autonomy, but not as a medical patient. The relevance of the medicalisation of her condition is removed. Other interviewees explicitly denied the relevance of medicine, such as Derrick, a gay man, who, when referring to his social infertility, explained: 'I didn't seek out any medical information because it wasn't relevant I think to my situation'.

The refusal of interviewees to use the medical diagnosis of infertility confirms the gap between a medicalised construct of identity and personal control over one's own identity. The label of infertility was only used by interviewees a handful of times, and only when repeating the ascription of characteristics or associated symptoms given to it as a disease by the medical profession, or reiterating a diagnosis given by practitioners. The interviewees' experiences capture a one-way transmission of information from the profession, which is 
more characteristic of a paternalistic style of medicine. For example, Abbie explained that 'we had sort of unexplained infertility, but you know, when they don't really know and you've got a fairly low egg count and egg quality'. Ethan, a member of a couple, noted sarcastically that 'it got called unexplained infertility, which is always helpful'. Ethan's sarcasm both reinforces the unwanted imposition of the term by the medical profession, and reflects his scepticism about the label's meaning when the 'disease' cannot be explained or cured. The only other usage of the term was either associated with characteristics of the disease - 'With infertility you can get used to all the different stages of grief'.

Medicalisation of infertility results in importing medical understandings into the appropriateness of desire for, use of, and restrictions to treatment (see Smart 2002: 110-113), a process which feminist scholars have long identified as having a negative impact upon women's bodies (Rich 1977; Rowland 1987). Greil et al. (1988) found that gender plays a crucial role in how men and women experience infertility, with women feeling that their inability to have children is stigmatizing and spoils their identities as women. Similarly, for the women in our cohort, the label of infertility had more of a negative impact. Some interviewees highlighted their distress at being identified in terms of their fertility, where the category ultimately became their primary identity. Paige stated:

I got married, knowing that was great practice for becoming a mum and then 15 years later we finally gave up and divorced because of the stress and strain of it all - of total unexplained infertility. There is everything - every test has always come back as perfect. It was just year after year after year of frustration and new additional tests. Then I started travelling outside of the country to figure out who I was.

Paige views her infertility as preventing her from becoming a mother, and forcing her to rethink her self-identity. The impossibility of using medical technology to cure 
her infertility framed her individual identity and choice-making in her decision to create a family. The use of medical technology is instrumental in Paige's narrative, as it is in almost all of the experiences of our interviewees.

\subsection{The Consumer}

\subsubsection{Technology and cost}

Franklin (2013) observes that it has become 'normal' to choose technology as the cure for infertility. The infertility industry caters for this demand. The medicalisation of infertility is based on a private medicalised market, which results in a for-profit, business structure of healthcare provision. This marketplace is funded by government subsidies and by users. Since the early 1990s, a co-payment system under Medicare has publicly subsidised treatment, but there are routinely large gaps between fees set by the clinic and subsidy payments (Chambers et al. 2013). Women from more affluent backgrounds use more ART treatment than poorer women, reflecting both a greater ability to pay for treatment and a greater need for ART treatment, as indicated by the Western trend to later childbearing (Chambers et al. 2013).

Across our interviewees, the expense of treatment was high. When asked to estimate cost, typical comments were that 'the money was extreme' (Jane), 'the costs are very high' (Zara), or, as one interviewee described, 'during the time that we did IVF, the cost doubled. It just went up - every six months, there'd be a letter saying, costs have gone up. They would go up by, I don't know, $\$ 500-\$ 800$ each time'. Estimates of up to AU\$100,000 for domestic altruistic surrogacy, and up to AU\$250,000 for surrogacy in the United States were not unusual. As Carys, an intending parent for surrogacy, observed, she:

...did 10 IVF cycles. So roughly at about $\$ 5000$ each after Medicare - so what is that - like roughly about $\$ 50,000$ in transfers. We did six transfers at about $\$ 5000$ a pop. So there's $\$ 30,000$. So we're at $\$ 80,000$ just fertility treatments. 
Another interviewee, Lauren, says:

Yeah, so, the lawyers both together have been $\$ 3000$. The counselling I'd say all up has probably been about $\$ 1500 \ldots$, let's say $\$ 3000$ in travel. So what's that eight, nine, 10 , $11,12,13,14,15, \$ 15,500$. Which is pretty cheap [so far].

One married interviewee, when asked about the pros and cons of the pathway that she and her husband had taken, responded:

I don't know if there's any pros. I felt like - I feel like - this is my personal opinion and the IVF doctor in America agrees with me - I don't think Australian IVF doctors are very honest. I mean probably some of them are but I think it gets to a certain point where their honesty needs to come into it - some people are just not going to produce a child and I don't think that they do that in Australia. They just don't tell you that. They just keep saying it's a numbers game. I got told that so many times - it's a numbers game, it's a numbers game. When you walk out of the parking lot and you're on transfer number 20 and there's three Bentleys parked in the carpark, you start to think mm, is it a numbers game or am I just lining your wallet. I don't know.

Australia is not alone with these critical and cynical observations as to cost and commerce. In Spain and Israel the impact of private commercial interest on regulations is resulting in excessive practices such as the repeat of ineffective cycles and the push of sometimes unnecessary treatment add-ons (Alon et al. 2019).

Alongside the large amounts of money paid, there was a recurrent theme about who was receiving the payments, as the marketplace extends well beyond the medical profession. One of the interviewees, Lachlan, described the different professionals paid in relation to the birth of his son, Alastair: 
So including IVF treatment it was about $\$ 80,000$ that we spent out of our own pocket with Alastair. That went to either the medical profession or the legal profession. It's quite clear that there's no sympathy involved, they've got quite every piece of the puzzle has got an extravagant fee, even for the ethics panel there was a fee. You think what is - it just seems - I can only - it just seemed to be different economy in terms of pricing as well. You have no option there, you're limited in terms of the number of providers in the case. So you're sort of well, okay, I need to bear that cost.

Lachlan's comments concerning the lack of options and choice squarely raises the issue of autonomy and gaps in protection offered by fertility industry practice regulation for patients. ${ }^{4}$ Lachlan's description paints a picture of a monopoly of few providers and little choice, with an inference that any option to stop is not viable. Instead of stopping, many interviewees consider themselves to be 'lucky' to be able to afford the services offered:

We're just lucky that we can afford to do what we do. There are a lot of people out there who can't, and they would have given up on their dreams of being parents. We're just - like if we didn't have our business, there's no way we could afford to keep doing IVF. We've already spent 80,000 dollars.

And noted that they would spend what they had to, whatever that may be:

The short answer is I think it cost too much. The long answer is what are you prepared to pay for a child? What is a child worth? Who should get the money? Are we paying the right people? (Cybil)

Being 'lucky' to pay large amounts to access ART treatments reveals how patients in the commercial infertility industry are uncomfortable bedfellows. The hope of the consumer that

\footnotetext{
${ }^{4}$ This can be seen across medical law; see, for example, the use of the Bolam test for negligence (Brazier and Miola 2000).
} 
medical treatment will 'work' pushes the individual in directions that are masked as rational free will and choice under the guise of medical autonomy. The result for many interviewees is exorbitant charges and little choice of providers and assistance.

Consumers also face a confusing marketplace in terms of choice of clinic and services, with the marketplace itself subject to unscrupulous behavior. In the United States, the fertility industry is described as the 'Wild West' (Paul 2004; Spar 2011), with fertility practitioners being referred to as 'cowboys' (Knoepfler 2016). The perception of a fertility industry that 'peddles false hope' (Kidspot 2016), and centres its own profits before patient care, is not restricted to the US. Recent crackdowns have been announced in the UK due to allegations that some clinics exploit low-income women to egg share (Bentley et al. 2017). In Australia, Virtus Health controversially ${ }^{5}$ announced a "High Performer Share Incentive Scheme", offering large cash to doctors who deliver more than 400 cycles per annum over a 3 -year period (Virtus Health 2018). Virtus later stated that the bonus would have 'no influence at all on clinic practice' (Virtus Health 2017). Recently, the Australian Competition and Consumer Commission forced several major IVF clinics to change claims published on their websites about IVF success rates following an investigation into potentially false or misleading representations.

\subsubsection{Believing in miracles: The absence of free will and choice and the industry}

Recent research confirms that, while patients have become more 'consumerist in their approach' (Hall et al. 2001; Lupton et al. 1991; Zadoroznyj 2001), they also believe in treatment by doctors and medical science. Reproductive medicine thus acts to create certainty where there is ambiguity. Gerritt's (2014) ethnographic study of patient centred fertility care in a Dutch clinic confirms a loss of rational decision making in ART patients. Gerritt's study

\footnotetext{
${ }^{5}$ One journalist calling it "terrifying” (Price 2017).
} 
found that, while patient centred care seems to give more power over decision making to patients, at the same time, because the interpersonal focus in patient centred care builds an intimacy between patients and clinic staff, it also means patients become more dependent on doctors and take a less active role in decision making, diminishing patient agency.

This loss of free will in decision making is also apparent amongst our cohort: But there's also that little bit of you that says, you're not a worthwhile person unless you have kids...Intellectually I don't believe in it, but emotionally it has been present all my life. (Millie)

I had this drive to basically keep going because if you're going to try long enough you are going to get there. (Helen)

As Shelby, who travelled to South Africa for egg donation, states: ...when I look at the entire IVF process I think I blindly followed my doctor's advice for the first six cycles...I just had faith it was going to work...I didn’t really understand just how tenuous it all is and the fact that it's not the golden ticket.

Shelby's comments indicate a sense of unquestioning trust in medicine, science and technology. The notion that IVF is the 'golden ticket' is a common misconception amongst our interviewees, confirming a shared belief that science is the winning cure for infertility. By prioritising the potential offered by technology as a cure, our interviewees defer to, privilege and support the expertise of medicine.

In this context, autonomy is impacted by the conflation of research and treatment, where technological advancement is success in and of itself. For example, Virtus has recently been engaging software companies to develop their 'IVY' artificial intelligence program which is being used to select the 'best' embryo for transfer, that is, embryos which are more likely to 
result in a heartbeat (LaFrenz 2018; see also Australian Business Register n.d.). Scientific research like this is used to reinforce the certainty of IVF. It may also be used to treat noninfertile patients for problems that are not related to infertility, where IVF is undertaken as an elective procedure for the purposes of genetic diagnosis, or where egg freezing is used by those who anticipate a future diagnosis of infertility (Salleh 2018). The miracle of having a child is slowly transformed by the misleading creation of scientific certainty, when no such certainty exists.

\subsection{The Traveller}

International studies establish that patients have difficulty putting a stop to treatment (Greil et al. 2010), as there is a persistent belief that a miracle will occur. The decision to travel across borders, often illegally, becomes a logical extension of fertility treatment, where many of our interviewees go further and further down a path in hope of success and form intimate relationships with specific clinics, agents (Millbank 2018), and physicians in the other jurisdiction. ${ }^{6}$ Travel, as an extension of unsuccessful fertility treatment, becomes the only rational choice, with the alternative to travel being acceptance of childlessness.

\subsubsection{Desperation, risk and fear}

The decision to travel is made against a backdrop of a pervasive industry, a dominating narrative of technology as cure, an air of finality, and a sense of desperation, risk and fear. Assessment of risk is itself medicalised, as it is made by comparing clinical standards, removing natural conception as a point of comparison (Sandelowski 1991: 41), and instead

\footnotetext{
${ }^{6}$ This is supported by research findings that fertility patients highly value interpersonal relationships with doctors, and individualised care, especially given the emotional nature of fertility treatment (see Dancet et al. 2011; Malin et al. 2001; van Empel et al. 2011)
} 
employing a 'least worst' approach. For example, Tasha identified risk as follows:

You're putting your trust in donors that are overseas and they're not being regulated by your own government so you're not sure if everything is done above board. That's why I chose America, because I thought it would be less likely for there to be a lot of dodgy things going on.

Tasha's decision making is made within an external context that is disempowering. She is not choosing America for what it offers her, but rather because it is likely to be 'less dodgy'. She therefore acknowledges personal and economic risk. This desperation and knowledge of risk is similarly described by Derrick, a gay man travelling for surrogacy, who explained that '[y]ou're handing over thousands or tens of thousands of dollars to some random stranger in a foreign country and, you know, it would be nice to know that the whole thing isn't a Nigerian scam'. The loss of control and willingness to pursue a family, at great risk, is palpable.

\subsubsection{A double voiced discourse of autonomy}

As Tasha and Derrick's comments reveal, fertility travellers base their accountability relationships with clinics on subjective trust, rather than on objective compliance with specific standards of performance. ${ }^{7}$ For most interviewees, the decision to travel across borders was a last resort, and a difficult option to take. For many interviewees, when help was withdrawn by the domestic regulatory framework, the cross-border clinic filled the vacuum of care, often becoming the sole point of reference for the health and well-being of the cross-border reproductive traveller. As Rosalind, who underwent egg donation in Greece with her husband, observed, 'We obviously put all our trust and all our faith into the doctor'. Travellers lose autonomy as the clinic becomes the facilitator, the connection between the

\footnotetext{
${ }^{7}$ Unlike, for example, the fair trade movement (see Davenport and Low 2013: 89).
} 
traveller and third parties (Krolokke 2017: 62), the point of trust, and the provider of its own accountability.

However, while travellers lose control, they are also keenly aware of the impact they have on the vulnerable third parties who assist them to create a family. Tom, who travelled to India for surrogacy, said of paying the surrogate: 'I wanted to hand over the final payment. Just to ensure there was nothing fishy going on'. Shirley, who similarly travelled to India, said: 'You're told lots of things about the surrogate which you just believe', following which she laughed, indicating she did not believe these things at all.

The obvious discomfort Tom and Shirley feel about the process of international surrogacy reveals their willingness to exploit others to pursue family creation. This is demonstrated by their self-rationalisation of what may well be poorly placed trust at the clinic level. While they hand over their own autonomy to the overseas clinic, they simultaneously use the autonomy of the third party surrogates and donors to justify their actions. In particular, they suggest they are giving autonomy to the surrogate, or providing them with autonomy. Tom said he was:

... a bit concerned around ethical issues of surrogacy in developing countries that some women might go through and possible messy legal situations and human rights and all that jazz...I think for me as well, everyone generally benefited from it if it was a good situation...the women have certain rights and protections and the intending parents do as well. Then there is I guess the financial benefits and other benefits of a surrogate being able to carry a baby and the outcome for that in a developing country...they can buy a home or out their kids through school. So that's a really, really good outcome, and we could get to have a baby.

In comparison, Tom said that he was 'questioning the...motivations' of Australian third party surrogates. Similarly, Shirley stated that: 
I am not sure that our society is really well engineered for surrogacy here...I

think it's a little bit different in India...for any first world country I would want to know a bit more about the motives of a surrogate in America for example...At least in India its very - you know exactly what the motivation is. You know its money. You know they - the surrogate does not want to keep your baby. They do not want another mouth to feed.

Tom and Shirley's accounts capture a double voiced discourse of autonomy. The traveller is simultaneously powerful and powerless, and they acknowledge that the surrogate may well be so too. On the one hand, travellers are aware of the line they cross between legality and illegality and wealth and poverty, and rationalise their decision by saying '[w]e're not trying to work the system, we're trying to create a family' (Beth), or that '...there's a part of me that's outraged. How dare somebody - how dare anybody tell me that I can't find a way to have a child' (Isaac). On the other hand, the travellers put themselves at risk, and are victims of the global industry. As one interviewee, Rita, pithily puts it, 'the experience has been fairly shattering' and going to a foreign country is 'terrifying'.

\section{Discussion}

The aim of this paper is to examine the application of the ethical principle of autonomy in the lived experience of individuals who have travelled for CBRC. This principle was explored across the three identity categories shared by the interview cohort: patient, consumer, and traveller. Across all three categories, the interviewees jointly and individually construct narratives which suggest a loss of control over their ability to stop medical treatment. All interviewees made autonomous choices to travel for CBRC, however their choices were influenced by access to technology, encouragement to use technology, and a feeling that they could not refuse treatment. 
This finding suggests that the practical application of the ethical principles of autonomy in travel for CBRC is contradictory. In choosing medical care, fertility clinics, and travel, the interviewees exercise autonomy. However, they are also confronted with a precarious situation where the promise of technology will clearly not be fulfilled if they stop treatment. This encourages them to keep trying, even when the avenues they undertake are expensive, painful and harmful, seemingly futile, and exploitative to others. This experience of recurring harm defies the more basic attributes of autonomy which, in Dworkin's terms, include 'dignity, integrity, individuality, independence, responsibility and self-knowledge', as well as 'critical reflection, with freedom from obligation, with absence of external causation, with knowledge of one's own interests' (Dworkin 1988: 127).

The contradiction arises in multiple ways:

- First, individuals who cross borders garner risk of significant physical, psychological, emotional and economic cost, both for the traveller and third party surrogates and donors. However, it is also apparent that they have much to gain psychologically, economically and emotionally from travel for CBRC.

- Second, the prioritisation of medicalised treatments for infertility masks the fact that travel for CBRC is necessarily a shared endeavour. For example, for gay men such as Tom, CRBC is the shared endeavour of the women who helped him - the egg donor and the surrogate - although these women disappear in the focus of infertility, as the infertility is Tom's alone. Similar to Mendel's (2007) argument concerning filial consent to medical treatment, more communitarian models may allow for consent to be owned by all with shared outcomes (Nedelsky 1989).

- Third, while IVF is a medical procedure, it is also a process of socially determined choices (Conrad and Barker 2010; Pierret 2003). As Culley et al. (2009) assert, '[T]he most important decisions that people make-to define themselves as infertile, to seek treatment (or not), to 
decide between forms of treatment, to consider adoption or other alternatives and so on-are all part of a fundamentally social process'. This explains the divergence between the social needs of infertile individuals to create a family, and the medical need to provide technology as the cure. Autonomy is compromised as the regulatory framework prioritises the treatment of the disease through technology, whereas for interviewees, the technology is secondary to the objective of family creation.

Further, when the bioethical principle of autonomy is examined from a bottom up sociological perspective, we see how the interviewees live a different reality of infertility to that which is medically defined. Across all interviewees, infertility as an abstract construct. It shapes and directs their decision making, yet they each reject the medical terminology as a description. This may be an attempt to minimise harm, as for many women infertility is the most upsetting experience of their lives, and levels of depression and anxiety in infertile patients are comparable with those in cancer patients. The aversion to using medical terminology marks a divergence between the medicalisation of infertility, and the interviewees' social reality (Lindemann 2018).

This finding of a contradictory application of autonomy departs from the findings of Couture et al. (2019) who determined, in one of the only empirical studies into Canadians travelling for $\mathrm{CBRC}$, that 'the problematic aspect of $\mathrm{CBRC}$ for users is the impression of being constrained to go abroad. In this perspective, CBRC without such constraint does not interfere with reproductive autonomy' (Couture et al. 2019: 44). While recognising that constraints to travel impact autonomy, this study finds that the inability of infertile individuals to be offered or engage with plausible alternative means of family creation leads to a situation where autonomy is compromised. This leaves infertile individuals with neither effective treatment nor meaningful autonomy. Where trust is so critical and the industry so commercial, the potential for abuse is considerable. 
The mismatch between the autonomy expected of a patient who consents to treatment, and the experience of the interviewees being unable, in a Kantian sense, to 'determine their own moral destiny', suggests a need to shift this field of study. How this is to be done is the subject for future research. One possibility is to create a new research agenda around the application of complementary ethical principles to autonomy, specifically beneficence, nonmaleficence and justice (Beauchamp and Childress 2001). To date, there are limited instances of these principles being applied to third party assisted reproduction. Two exceptions are the Principle of Procreative Beneficence (Savulescu and Kahane 2009) and reproductive justice in transnational surrogacy (Bailey 2011), and posthumous sperm (Lawson et al. 2016). Whereas autonomy respects the decision-making capacities of autonomous persons, the focus of beneficence is to provide benefits to the individual, and the focus of non-maleficence is to avoid causing harm. Both principles place the needs of the patient first. Additionally, justice is the obligation of fairness in the distribution of benefits and risks, which allows a balancing of the competing principles to take place. The principles can be used together to more easily form a considered judgement of how best to proceed.

\section{Conclusion}

Autonomy for travellers for $\mathrm{CBRC}$ is a principle of contradictory application. Infertile individuals who travel exercise autonomy, in that they are in charge of their own interests (de Lacey 2002). Indeed, the fact that they engage with a global reproductive industry demonstrates agency and choice. However, the interviews also highlight that a significant consequence of a diagnosis of infertility is constraint of reproductive choice. This limits the autonomy of an infertile person across their experiences as patient, consumer, and traveller.

This empirical bioethics inquiry sheds light on how infertility permeates the lives of individuals and how infertility - not the individual - is supported by the regulatory 
framework. The framework medicalises infertility, which in turn shapes our understanding of infertility treatment as technology and science. Accordingly, to remain infertile is a decision, and to not attempt to cure it through technology is failure. Thus technology offers infertile individuals choice as well as no choice. Recognising the limits of autonomy in this field is one step towards reframing a more proportionate and responsive framework for the regulation of ART and related services.

\section{Acknowledgments}

This research was funded by Australian Research Council Grant DP 1510157. Thanks to Jenni Millbank, Isabel Karpin and Norman O’Dowd for comments on earlier versions of this paper; to Miranda Kaye, Norman O’Dowd, Rachel Carr, and Michaela Stockey-Bridge for research assistance on the project; and to our interview participants for sharing their views and thoughts.

\section{References}

Cresswell v Attorney-General for the State of Queensland [2018] QSC 142. Re Evelyn (1998) 145 FLR 90.

Alon, I., Guimon, J. \& Urbanos-Garrido, R. (2019). Regulatory responses to assisted reproductive technology: a comparative analysis of Spain and Israel. Journal of Assisted Reproduction and Genetics, 36(8), 1665-1681.

Australian Business Register. (n.d.). Current details for ABN 80129643 492. Retrieved October 11, 2019, from https://abr.business.gov.au/ABN/View?abn=80129643492. Australian Medical Council. (2009). Good Medical Practice: A Code of Conduct for Doctors 
in Australia. (Canberra: Australian Medical Council). Retrieved October 11, 2019, from https://www.amc.org.au/wp-

content/uploads/about/good medical practice/2009-07 Final Code.pdf.

Bailey, A. (2011). Reconceiving Surrogacy: Toward a Reproductive Justice Account of Indian Surrogacy. Hypatia, 26(4), 715-741.

Bartholomaeus, C. \& Riggs, D. W. (2018). Embryo donation and receipt in Australia: views on the meanings of embryos and kinship relations. New Genetics and Society, 38(1), $1-17$.

Beauchamp, T. L. (2004). Does Ethical Theory Have a Future in Bioethics? Journal of Law, Medicine \& Ethics, 32(2), 209-217.

Beauchamp, T. \& Childress, J. (2001). Principles of biomedical ethics. $5^{\text {th }}$ ed. (New York: Oxford University Press).

Beauchamp, T. L. \& Childress, J. F. (2009). Principles of biomedical ethics. $6^{\text {th }}$ ed. (New York: Oxford University Press).

Bell, A. V. (2010). Beyond (financial) accessibility: inequalities within the medicalisation of infertility. Sociology of Health \& Illness, 32(4), 631-646.

Bentley, P., Smyth, S. \& Faulkner, K. (2017). Crackdown on the IVF cowboys after probe reveals financial incentives to entice women into giving away eggs. Daily Mail, September 13. Retrieved October 11, 2019, from https://www.dailymail.co.uk/news/paper-4878048/Crackdown-IVF-cowboysprobe.html.

Brazier, M. \& Miola, J. (2000). Bye-bye Bolam: a medical litigation revolution? Medical Law Review, 8(1), 85-114.

Chambers, G. M., Hoang, V. P. \& Illingworth, P. J. (2013). Socioeconomic disparities in 
access to ART treatment and the differential impact of a policy that increased consumer costs. Human Reproduction, 28(11), 3111-3117.

Conrad, P. (1992). Medicalization and Social Control. Annual Review of Sociology, 18, 209232.

Conrad, P. \& Barker, K.K. (2010). The social construction of illness: key insights and policy implications. Journal of Health and Social Behavior, 51(Suppl), S67-9.

Conrad, P. \& Leiter, V. (2004). Medicalization, markets and consumers. Journal of Health and Social Behavior, 45(Extra Issue), 158-176.

Conrad, P., Mackie, T. \& Mehrotra, A. (2010). Estimating the cost of medicalization. Social Science \& Medicine, 70(2), 1943-1947.

Corea, G. (1985). The mother machine: Reproductive technologies from artificial insemination to artificial wombs. (New York: Harper \& Row).

Couture, V., Drouin, R., Moutquin, J., Monnier, P. \& Bouffard, C (2019). Reproductive outsourcing: an empirical ethics account of cross-border reproductive care in Canada. Journal of Medical Ethics, 45(1), 41-47.

Culley, L., Hudson, N. \& van Rooij, F. (2009). Introduction: Ethnicity, infertility and assisted reproductive technologies. (In L. Culley, N. Hudson, \& F. van Rooij (Eds.), Marginalized reproduction: Ethnicity, infertility, and reproductive technologies (pp. 1-14). London: Earthscan.)

Culley, L., Hudson, N., Rapport, F., Blyth, E., Norton, W. \& Pacey, A. A. (2011). Crossing borders for fertility treatment: motivations, destinations and outcomes of UK fertility travellers. Human Reproduction, 26(9), 2373-2381.

Dancet, E. A., Van Empel, I. W., Rober, P., Nelen, W. L., Kremer, J. A. \& D’Hoogheet, T. M. (2011). Patient-centred infertility care: a qualitative study to listen to the patient's voice. Human Reproduction, 26(4), 827-833. 
Davenport, E. \& Low, W. (2013). From trust to compliance: accountability in the fair trade movement. Social Enterprise Journal, 9(1), 88-101.

de Lacey, S. (2002). IVF as lottery or investment: contesting metaphors in discourses of infertility. Nursing Inquiry, 9(1), 43-51.

Donhcin, A. (2011). In Whose Interest? Policy and Politics in Assisted Reproduction. Bioethics, 25(2), 92-101.

Dorr Goold, S. \& Lipkin, M. (1999). The Doctor-Patient Relationship: Challenges, Opportunities and Strategies. Journal of General Internal Medicine, 14(1), 26-33.

Dworkin, G. (1988). The Theory and Practice of Autonomy. (Cambridge: Cambridge University Press, 1988).

Farrell, A., Devereux, J., Karpin, I. \& Weller, P. (2017). Health Law: Frameworks and Context. (Cambridge: Cambridge University Press).

FertilitySA. (2018). The top 3 reasons infertility is on the rise. FertilitySA, January 11. Retrieved October 11, 2019, from https:/fertilitysa.com.au/2018/01/11/the-top-3reasons-fertility-is-on-the-rise/.

Firestone, S. (1970). The dialectic of sex: The case for feminist revolution. (New York: Morrow).

Foster, C. (2009). Choosing Life, Choosing Death: The Tyranny of Autonomy in Medical Ethics and Law. (Oxford, UK: Hart).

Fox, R. C. \& Swazey, J. (2008). Observing Bioethics. (New York: Oxford University Press).

Franklin, S. (1997). Embodied Progress: A Cultural Account of Assisted Conception. (London and New York: Routledge).

Franklin, S. (2013). Conception Through a Looking Glass. Reproductive Biomedicine Online, 27(6), 747-755.

Gerrits, T. (2014). The ambiguity of patient-centred practices: the case of a Dutch fertility 
clinic. Anthropology \& Medicine, 21(2), 125-135.

Global Market Insights. (2016). Industry Trends: Assisted Reproductive Technology (ART) Market Size by Procedure. (Ocean View: Global Market Insights).

Gorton, M. (2019). Helping Victorians create families with assisted reproductive treatment: Final Report of the Independent Review of Assisted Reproductive Treatment. (Melbourne: Department of Health and Human Services).

Greil, A. L., Leitko, T. A. \& Porter, K. L. (1988). Infertility: His and hers. Gender and Society, 2(2), 172-199.

Greil, A. L., Slauson-Blevins, K. \& McQuillan, J. (2010). The Experience of Infertility: a review of recent literature. Sociology of Health and Illness, 32(1), 140-162.

Greil, A. L., McQuillan, J. \& Slauson-Blevins, K. (2011). The Social Construction of Infertility. Sociology Compass, 5(8), 736-746.

Hall, M. A., Dugan, E., Zheng, B. \& Mishra, A. K. (2001). Trust in Physicians and Medical Institutions: What Is It, Can It Be Measured, and Does It Matter? The Milbank Quarterly, 79(4), 613-639.

Hodsona, N. \& Bewley, S. (2019). Abuse in assisted reproductive technology: A systematic qualitative review and typology. European Journal of Obstetrics \& Gynecology and Reproductive Biology, 238, 170-177

Inhorn, M. C. \& Patrizio, P. (2009). Rethinking reproductive 'tourism' as reproductive 'exile'. Fertility and Sterility, 92(3), 904-906.

Inhorn, M. C. \& Patrizio, P. (2012). Procreative tourism: debating the meaning of crossborder reproductive care in the 21 st century. Expert Review of Obstetrics \& Gynecology, 7(6), 509-511.

Jackson, E., Millbank, J., Karpin, I. \& Stuhmcke, A. (2017). Learning from Cross-Border Reproduction. Medical Law Review, 25(1), 23-46. 
Jordan, C. B., Belar, C. D., Williams R. S. (2004). Anonymous oocyte donation: a follow-up analysis of donors' experiences. Journal of Psychosomatic Obstetric Gynaecology, $25(2), 145-151$.

Kidspot. (2016). IVF: “Our optimism drains away with every month”. Whimn, May 30.

Retrieved October 15, 2019, from

https://www.kidspot.com.au/birth/conception/ivf/ivf-our-optimism-drains-away-withevery-month/news-story/ddf011360977bb5e473a21b4e1089ef0.

Knoepfler, P. (2016). GMO Sapiens: The Life-Changing Science of Designer Babies.

(Singapore: World Scientific).

Krolokke, C. (2017). Negotiating Nationality and Fertility when Travelling for Eggs. (In M.

Lie \& N. Lykke (Eds.), Assisted Reproduction Across Borders: Feminist Perspectives on Normalizations, Disruptions and Transmissions (pp. 61-71). New York:

Routledge).

LaFrenz, C. (2018). Virtus Health says artificial intelligence has potential to make IVF babies. Australian Financial Review, June 27.

Law Reform Committee. (2012). Inquiry into Access by Donor-Conceived People to Information about Donors. (Melbourne: Parliament of Victoria). Retrieved October 11, 2019, from https://www.parliament.vic.gov.au/papers/govpub/VPARL201014No120.pdf.

Lawson, A. K., Zweifel, J. E. \& Klock, S. C. (2016). Blurring the line between life and death: a review of the psychological and ethical concerns related to posthumous-assisted reproduction. The European Journal of Contraception \& Reproductive Health Care, 21(5), 339-346.

Leyser-Whalen, O., Greil, A. L., McQuillan, J., Johnson, K. M. \& Shrefffler, K. M. (2018). 
'Just because a doctor says something, doesn't mean that [it] will happen': selfperception as having a Fertility Problem among Infertility Patients. Sociology of Health and Illness, 40(3), 445-462.

Lindemann, K. (2018). I'm a feminist. So why does infertility make me feel like a failure? The Guardian, November 2.

Lupton, D., Donaldson, C. \& Lloyd, P. (1991). Caveat emptor or blissful ignorance? Patients and the consumerist ethos. Social Science \& Medicine, 33(5), 559-568.

Mackenzie, C. \& Stoljar, N. (2000). Relational Autonomy: Feminist Perspectives on Autonomy, Agency, and the Social Self. (Oxford, UK: Oxford University Press).

Malin, M., Hemmink, E., Räikkönen. O, Sihvo, S. \& Perälä, M. L. (2001). What do women want? Women's experiences of infertility treatment. Social Science \& Medicine, 53(1), 123-133.

McLean, S. (2010). Autonomy, Consent and the Law. (London: Routledge).

Medical Board of Australia. (2018). Sexual boundaries in the doctor-patient relationship. Retrieved October 11, 2019, from https://www.medicalboard.gov.au/codesguidelines-policies/sexual-boundaries-guidelines.aspx.

Mendel, J. (2007). The patient, the doctor and the family as aspects of community: New models of informed consent. Monash Bioethics Review, 26(1-2), 68-78.

Meyers, D. T. (1989). Self, Society and Personal Choice. (New York: Columbia University Press).

Mill, J. S. (1909). On Liberty. (Boston: P. F. Collier \& Son).

Millbank, J. (2018). The role of professional facilitators in cross-border assisted reproduction. Reproductive Biomedicine and Society Online, 6, 60-71.

Millbank, J. (2019). What is the Responsibility of Australian Medical Professionals Whose Patients Travel Abroad for Assisted Reproduction? Medical Law Review, 27(3), 365- 
389.

Milligan, E. \& Jones, J. (2016). Rethinking Autonomy and Consent in Healthcare Ethics. (In P. A. Clark (Ed.), Bioethics - Medical, Ethical and Legal Perspectives. IntechOpen). Retrieved October 11, 2019, from https://www.intechopen.com/books/bioethics$\underline{\text { medical-ethical-and-legal-perspectives/rethinking-autonomy-and-consent-in- }}$ healthcare-ethics.

Montgomery, R. (2016). WHO considers new definition of infertility that includes being single. BIO News, October 24. Retrieved October 11, 2019, from https://www.bionews.org.uk/page 95744.

Morgan, K. (1998). Contested bodies, contested knowledges: women, health, and the politics of medicalisation. (In S. Sherwin (Ed.), The politics of women's health: exploring agency and autonomy (pp. 83-121). Philadelphia: Temple University Press).

Morgan, D. (1998). Frameworks of analysis for feminisms' accounts of reproductive technology. (In S. Sheldon (Ed.), Feminist Perspectives on Health Care Law (1 edition). London: Routledge-Cavendish).

Nahman, M. (2011). Reverse Traffic: Intersecting qualities in human egg donation. Reproductive Biomedicine Online, 23(5), 626-633.

Nedelsky, J. (1989). Reconceiving Autonomy: Sources, Thoughts and Possibilities. Yale Journal of Law and Feminism, 1, 7-36.

Paton, A. (2018). About time: how time influences and facilitates patient autonomy in the clinical encounter. Monash Bioethics Review, 36, 68-85.

Paul, M. (2004). Fertility clinics a 'wild west'. Chicago Tribune, February 4. Retrieved October 11, 2019, from https://www.chicagotribune.com/news/ct-xpm-2004-02-040402040021-story.htm1.

Pennings, G., de Wert, G., Shenfield, F., Cohen, J., Tarlatzis, B. \& Devroey, P. (2008). 
ESHRE Task Force on ethics and law 15: Cross-border reproductive care. Human Reproduction, 23(10), 2182-2184.

Pierret, J. (2003). The illness experience: state of knowledge and perspectives for research. Sociology of Health \& Illness, 25(3), 4-22.

Price, J. (2017). IVF: the only bonus paid should be a baby bonus. Sydney Morning Herald, September 11. Retrieved on October 11, 2019, from https://www.smh.com.au/opinion/ivf-the-only-bonus-paid-should-be-a-baby-bonus20170911-gyertn.html.

Purdy, L. (2006). Women's reproductive autonomy: medicalisation and beyond. Journal of Medical Ethics, 36, 287-291.

Rich, A. (1977). Of Women Born: Motherhood as Experience and Institution (London: Virago).

Rowland, R. (1987). Technology and Motherhood: Reproductive Choice Reconsidered. Signs, 12(3), 512-528.

Robertson, J. (1994). Children of choice: freedom and the new reproductive technologies. (Princeton: Princeton University Press).

Ross, H. L. (1982). Deterring the Drinking Driver: Legal Policy and Social Control. $2^{\text {nd }}$ ed. (Lexington, MA: D.C. Heath and Company).

Ross, H. L. (1992). Confronting Drunk Driving: Social Policy for Saving Lives. (New Haven, CT: Yale University Press).

Royal Australian and New Zealand College of Obstetricians and Gynaecologists. (2016). Cross Border Reproductive Care. Retrieved October 11, 2019, from https://ranzcog.edu.au/RANZCOG SITE/media/RANZCOGMEDIA/Women $\% 27 \mathrm{~s} \% 20$ Health/Statement $\% 20$ and $\% 20$ guidelines/Clinical $\% 20$ - 
\%20Gynaecology/Cross-Border-Reproductive-Care-(C-Gyn-36)-New-March2016.pdf?ext=.pdf.

Salleh, A. (2018). Egg timer test for fertility: What is it and does it work? ABC News, September 23. Retrieved October 11, 2019, from https://www.abc.net.au/news/science/2018-09-23/what-is-an-egg-timer-test-forfertility-and-does-it-work/10234086.

Sandel, M. J. (1982). Liberalism and the Limits of Justice. (New York: Cambridge University Press).

Sandelowski, M. (1991). Compelled to Try: The Never-Enough Quality of Conceptive technology. Medical Anthroplogy Quarterly, 5(1), 29-47.

Savulescu, J. \& Kahane, G. (2009). The Moral Obligation to Create Children with the Best Chance of the Best Life. Bioethics, 23(5), 274-290.

Schneider, C. E. (1998). The Practice of Autonomy. (New York: Oxford University Press). Sherwin, S. (1998). A Relational Approach to Autonomy in Health Care. (In S. Sherwin (Ed.), The Politics of Women's Health: Exploring Agency and Autonomy (pp. 19-47). Philadelphia: Temple University Press).

Smart, C. (2002). Feminism and the Power of Law. (New York: Routledge).

Snyder, J., Crooks, V. A., Johnston, R. \& Dharamsi, S. (2013). “Do Your Homework... and Then Hope for the Best": The Challenges That Medical Tourism Poses to Canadian Family Physicians' Support of Patients’ Informed Decision-Making. BMC Medical Ethics, 14, 37.

Spar, D. L. (2011). Fertility Industry is a Wild West, September 13. Retrieved October 11, 2019, from https://www.nytimes.com/roomfordebate/2011/09/13/making-laws-aboutmaking-babies/fertility-industry-is-a-wild-west.

Speier, A. (2016). Fertility Holidays: IVF Tourism and The Reproduction of Whiteness. 
(New York: New York University Press).

Storrow, R. (2010). The pluralism problem in cross border reproductive care. Human Reproduction, 25(12), 2939-2943.

van Empel, I. W., Dancet, E. A., Koolman, X. H., Nelen, W. L., Stolk, E. A., Sermeus, W., D’Hooghe, T. M. \& Kremer J. A. (2011). Physicians underestimate the importance of patient-centredness to patients: a discrete choice experiment in fertility care. Human Reproduction, 26(3), 584-593.

Virtus Health. (2017). Virtus Health Australia's leading Fertility group delivers patient care.

September 17. Retrieved October 11, 2019, from https://www.virtushealth.com.au/virtushealth-australia's-leading-fertility-group-delivers-patient-care.

Virtus Health. (2018). Annual Report. (Sydney: Virtus Health).

Wangmo, T. \& Provoost, V. (2017). The use of empirical research in bioethics: a survey of researchers in twelve European countries. BMC Medical Ethics, 18, 79.

Waldby, C. (2019). The Oocyte Economy. (Durham, N.C.: Duke University Press).

Waldby, C. \& Cooper, M. (2008). The biopolitics of reproduction. Australian Feminist Studies, 23(55), 57-73.

Whittaker, A. \& Speier, A. (2010). 'Cycling overseas': care, commodification, and stratification in cross-border reproductive travel. Medical Anthropology, 29(4), 363383.

World Health Organisation (n.d.). Infertility definitions and terminology. Retrieved October 11,2019, from

https://www.who.int/reproductivehealth/topics/infertility/definitions/en/.

Zadoroznyj, M. (2001). Birth and the "reflexive consumer": trust, risk and medical dominance in obstetric encounters. Journal of Sociology, 37(2), 117-139. 
